\title{
Complete nucleotide sequence of the Oenothera elata plastid chromosome, representing plastome I of the five distinguishable Euoenothera plastomes
}

\author{
H. Hupfer · M. Swiatek · S. Hornung • R. G. Herrmann • \\ R. M. Maier $\cdot$ W.-L. Chiu $\cdot$ B. Sears
}

Published online: 22 August 2008

(C) Springer-Verlag 2008

\section{Erratum to: Mol Gen Genet (2000) 263:581-585 DOI 10.1007/PL00008686}

Continued sequencing of Oenothera plastid chromosomes in our laboratory has led to the discovery of various errors in the published plastome I sequence (Hupfer et al. 2000). Some of these errors have also been noted by others [Rice DW, Palmer JD (2006) BMC Biol 4:31]. We have now re-sequenced the plastome I chromosome [Greiner S, Wang X, Rauwolf U, Silber MV, Mayer K, Meurer J, Harberer G, Herrmann RG (2008) The complete nucleotide sequences of the five genetically distinct plastid genomes of Oenothera subsection Oenothera: I. Sequence evaluation and plastome evolution. Nucleic Acids Res 36:2366-2378] and deposited the revised sequence in GenBank under the accession no. AJ271079.3. This submission supersedes the previously submitted sequences with the accession nos. AJ271079.1 and AJ271079.2. We wish to emphasize that the basic inferences drawn in the original publication (Hupfer et al. 2000) remain unchanged. We sincerely regret any inconvenience caused by the publication of the original data.

The online version of the original article can be found under doi: 10.1007/PL00008686.

H. Hupfer $\cdot$ M. Swiatek $\cdot$ S. Hornung

R. G. Herrmann $(\varangle) \cdot$ R. M. Maier

Botanisches Institut der Ludwig-Maximilians-Universität,

Menzinger Strasse 67, D-80638 München, Germany

e-mail: herrmann@botanik.biologie.uni-muenchen.de

W.-L. Chiu $\cdot$ B. Sears

Department of Botany and Plant Pathology,

Michigan State University, East Lansing, MI 48824, USA 